\title{
Development and Performing of a Method of Comparative Flammability Tests of Magnesium Alloys
}

\author{
Sergey Barbot'ko', Oleg Volniy ${ }^{1}$, Nikolai Trofimov ${ }^{1}$, Aleksandr Leonov ${ }^{1}$, Andrei \\ Sivenkov ${ }^{2}$, and Marina Gravit ${ }^{3 *}$ \\ ${ }^{1}$ Federal State Unitary Enterprise «ALL-RUSSIAN SCIENTIFIC RESEARCH INSTITUTE OF \\ AVIATION MATERIALS», 105005, Radio st., 17, Moscow, Russia \\ ${ }^{2}$ Academy of the State Fire Service of Emercom of Russia, 129366, Boris Galushkin st, 4, Moscow, \\ Russia \\ ${ }^{3}$ Peter the Great St. Petersburg Polytechnic University, 195521 Polytechnicheskaya, 29, Saint- \\ Petersburg, Russia
}

\begin{abstract}
Magnesium alloys find their application in aviation technology for manufacturing of structural elements in uninhabited compartments and outside areas with increased fire hazard. At the stage of development of magnesium alloys with low fire hazard, it is advisable to perform comparative tests on relatively small samples so that all test equipment can be located in a laboratory. A method has been developed for conducting flammability tests when exposed to a flame with a temperature of $1,100^{\circ} \mathrm{C}$ for samples of magnesium alloys of small sizes. Comparative tests of two magnesium alloys - the standard ML5 and the new experimental one with increased fire safety - have been carried out. Significant differences have been established in the flammability and extinguishing ability of various grades of magnesium alloys - it is shown that the samples of the experimental magnesium alloy, in comparison with the ML5 alloy, are more difficult to ignite and in most cases can self-extinguish rapidly, while the weight loss of the sample practically does not occur.
\end{abstract}

\section{Introduction}

Magnesium alloys, in comparison with aluminum alloys, have a lower density and better physical and mechanical characteristics. Therefore, when replacing parts made of aluminum alloys with those made of magnesium alloys, weight saving reaches $25-30 \%$. In this regard, the wider application of magnesium alloys as structural materials is extremely promising [14].

However, the use of magnesium alloys is constrained by some of their disadvantages. One of the reasons is the high flammability of magnesium and most of its alloys. As a result, in aviation technology, magnesium alloys are used for the manufacture of structural elements in uninhabited compartments and outside areas with increased fire hazard.

\footnotetext{
*Corresponding author: marina.gravit@mail.ru
} 
The heat of combustion of aluminum is $31.087 \mathrm{~kJ} / \mathrm{g}$, magnesium $-25 \mathrm{~kJ} / \mathrm{g}[5,6]$. However, usually under fire conditions, compact products made of aluminum alloys only melt, but do not ignite, and most magnesium alloys ignite with the formation of a hightemperature combustion center with a temperature of more than $2500{ }^{\circ} \mathrm{C}$. The difference in the behavior of aluminum and magnesium in a fire is explained by the difference in the structure of the crystal lattice of the oxides of these metals: aluminum oxide on the surface forms a dense film that prevents the contact of the unreacted metal with the oxidizing agent, and magnesium oxide is a loose gas-permeable structure. Therefore, it is possible to reduce the ignition ability of magnesium alloys either with the help of special coatings created on the surface $[7,8]$, or by introducing special alloying elements (for example, calcium, rare earth elements) into the alloy composition [9].

For many years, there has been a restriction on the use of magnesium alloys in passenger cabins. For example, according to the technical standard TSO C127 "Rotorcraft and Transport Airplane Seating Systems" developed by the US Federal Aviation Administration (FAA), the minimum requirements for aircraft seats must meet the aviation standard of the International Society of Automotive Engineers - SAE) - AS 8049 "Performance Standard for Seats in Civil Rotorcraft, Transport Aircraft, and General Aviation Aircraft". Paragraph 3.3.3 of AS 8049 (revision A) said: "Magnesium alloys shall not be used". Magnesium alloy means any solid material containing at least $10 \%$ magnesium in its composition. Thus, these documents (TSO C127 and SAE AS 8049) blocked the use of magnesium alloys in aircraft seat designs.

Obtaining a possible weight benefit in the case of using magnesium alloys instead of aluminum alloys initiated work in the development of alloying systems, both in Russia and abroad $[3,4,7,10-13]$.

To assess the fire hazard of magnesium alloys, the FAA Technical Center conducted studies [14 - 16] and developed laboratory test procedures [17] included in sections 25 and 26 of the current Aircraft Materials Fire Test Handbook $[18,19]$.

Laboratory fire tests have shown that new alloys containing rare earth elements are fire safe. This conclusion was also confirmed by full-scale fire tests of the aircraft fuselage compartment [16]. Based on the results of the studies carried out in August 2015, the AS 8049 revision was revised and magnesium alloys were approved for use in passenger cabins [20].

The developed method of fire testing of samples of magnesium alloys for the manufacturing of structural elements of seats, set forth in section 25 of the current Handbook on methods of fire testing of aviation materials, requires the use of relatively large samples of a powerful kerosene burner.

Figure 1 below shows a scheme of the test equipment.

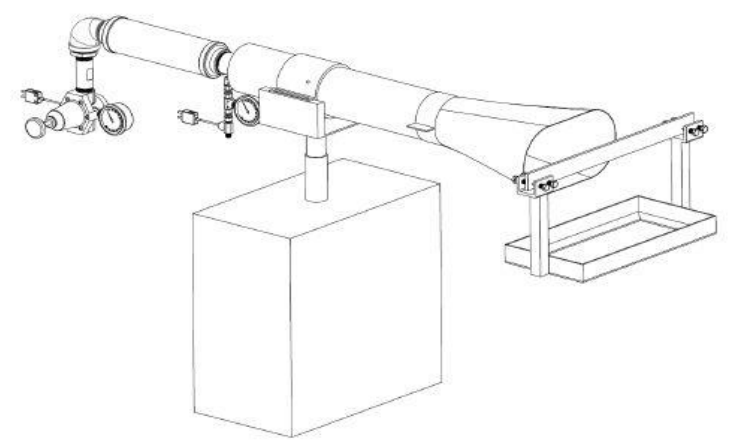

Fig. 1. Scheme of test equipment for fire tests of magnesium alloy samples when exposed to the flame of a kerosene burner (Section 25 Aircraft Materials Fire Test Handbook) [18] 
Testing samples have dimensions: length $508 \mathrm{~mm}$, height $38 \mathrm{~mm}$, thickness $6.4 \mathrm{~mm}$.

A 2 gph kerosene burner produces a flame that has a temperature of $1700 \pm 100{ }^{\circ} \mathrm{F}(927$ $\pm 55^{\circ} \mathrm{C}$ ). The duration of the exposure of the samples to the flame is 4 minutes. To organize a site for conducting fire tests in accordance with this method, a separate specially equipped room is required (preferably a separate building). Fire safety requirements: no sample should ignite earlier than $2 \mathrm{~min}$, the weight loss of samples after testing should not exceed $10 \%$.

Problems with the organization of a separate special site for conducting fire tests and the need to manufacture large-sized samples make the use of this technique impractical at the stage of prospecting work. A small-scale technique has been proposed by Airbus Corporation using a Teklu burner with a flame temperature of about $1100^{\circ} \mathrm{C}$ (Fig. 2) [21].

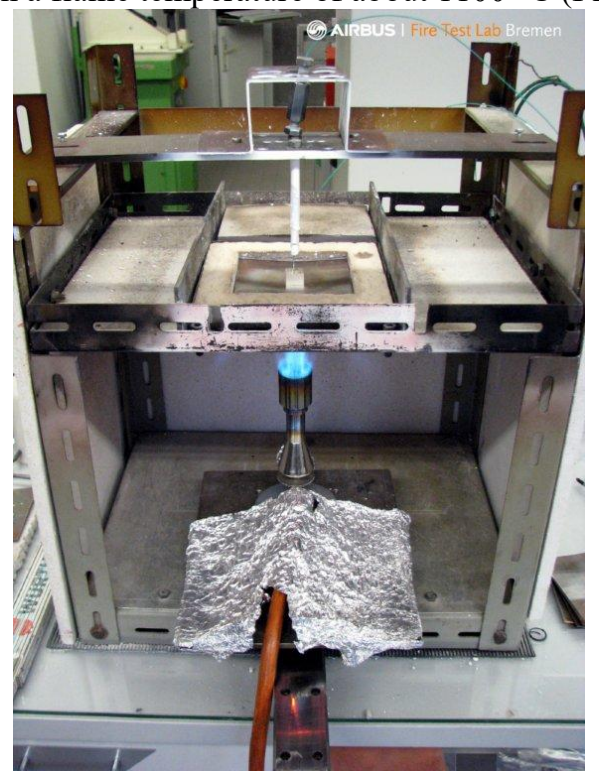

Fig. 2. Small-sized installation for fire tests of flammability of magnesium alloy samples [21]

However, in the technique proposed by Airbus, there is no direct contact between flame and the test sample (the sample is placed on a steel sheet heated from below by the flame of a gas burner).

In this regard, the task was set to develop a test procedure for small-sized samples when exposed to a flame with a temperature of $1100{ }^{\circ} \mathrm{C}$. The work was carried out within the framework of the implementation of complex scientific problem 2.2. "Qualification and research of materials" of strategic direction 2. "Fundamental-oriented research, qualification of materials and non-destructive testing" and 8.4 "High-strength corrosion-resistant weldable magnesium and cast aluminum alloys for new generation aerospace products." ("Strategic directions for the development of materials and technologies for their processing for the period up to 2030") [22,23].

\section{Materials and methods}

Comparative fire tests were carried out on samples of the ML5 magnesium alloy and a new experimental alloy with improved fire safety (OPBS).

As already noted, at the stage of materials development, carrying out standardized fire tests, on the one hand, requires significant costs for the manufacturing of large samples, and on the other hand, it can pose a very high fire hazard. Therefore, at the stage of prospecting for the development of magnesium alloys with improved fire safety, it is advisable to perform 
preliminary comparative tests on relatively small samples so that all test equipment can be located in a laboratory fume hood.

To develop a methodology for comparative flammability tests of magnesium alloy samples for, a tooling was made, the scheme of which is shown in Fig. 3.

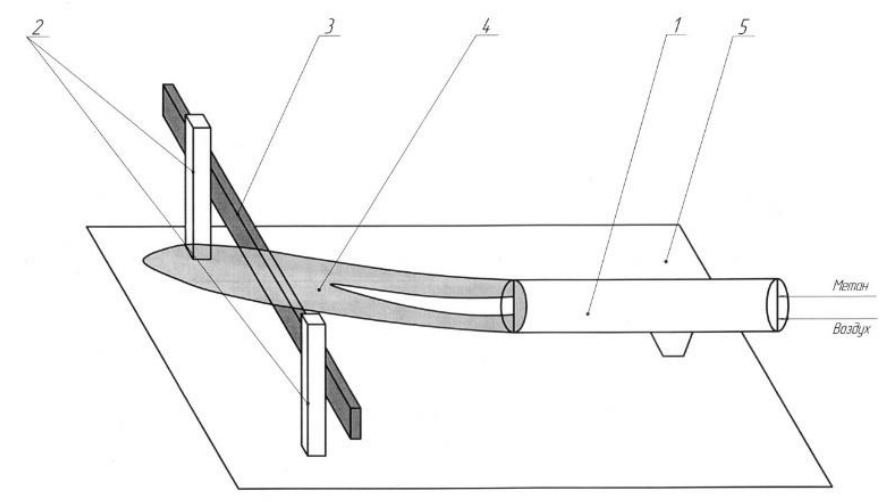

Fig. 3. Scheme of equipment for comparative flammability tests of magnesium alloy samples when exposed to a flame with a temperature of $1100{ }^{\circ} \mathrm{C}$ : 1 - gas burner, 2 - stands for fastening the test samples, 3 - sample, 4 - gas burner flame, 5 - metal basis.

A gas burner flame was used as an ignition source. The flame temperature in the area of impact on the test specimen was $1100_{-}(-50)^{\wedge}(+80)^{\circ} \mathrm{C}$. For the tests, a gas burner with a nozzle diameter of $40 \mathrm{~mm}$ was used, the fuel was methane gas, and the oxidant was air. The burner creates a stable premixed flame due to the forced supply to the combustion zone at the same time: a mixture of methane + air (central inner part of the flame), air (middle part of the flame) and methane (outer part of the flame).

Several test options were tested:

Option 1 - Tests of short, cantilevered specimens, duration of exposure to burner flame 1 minute.

Option 2 - Tests of short, cantilevered specimens, exposure time to burner flame 2 minutes.

Option 3 - Tests of short samples mounted on a block made of heat-insulating material, duration of exposure to the burner flame is 2 minutes.

Variant 4 - Tests of long specimens, fixed at two points, duration of exposure to burner flame 2 minutes.

Option 5 - Tests of long specimens, fixed at two points with an asbestos fabric backing, duration of exposure to burner flame 2 or 4 minutes.

When using option 5, during testing, it is possible to install a thermocouple sensor in the samples and control the temperature of the sample in the zone of exposure to the flame.

\section{Results and discussion}

The tests were carried out on samples of a standard widespread magnesium alloy (ML5) and an experimental fireproof alloy (symbol in the table - OPBS). The results are shown in Table 1.

Table 1. Results of flammability testing of samples of magnesium alloys when exposed to a flame with a temperature of $1,100^{\circ} \mathrm{C}$.

\begin{tabular}{|c|c|c|c|c|c|c|c|c|}
\hline $\begin{array}{c}\text { Sample } \\
\text { No. }\end{array}$ & $\begin{array}{c}\text { Type } \\
\text { of } \\
\text { alloy }\end{array}$ & $\begin{array}{c}\text { Size of sample } \\
\text { (LxWxT) }\end{array}$ & $\begin{array}{c}\text { Time of flame } \\
\text { exposure, min }\end{array}$ & $\begin{array}{c}\text { Time of } \\
\text { ignition, s }\end{array}$ & $\begin{array}{c}\text { Time of } \\
\text { burning after } \\
\text { removing the }\end{array}$ & $\begin{array}{c}\text { Initial } \\
\text { sample } \\
\text { weight, }\end{array}$ & $\begin{array}{c}\text { Weight of } \\
\text { sample residue, g }\end{array}$ & $\begin{array}{c}\text { Mass } \\
\text { loss, } \\
\%\end{array}$ \\
\hline
\end{tabular}




\begin{tabular}{|c|c|c|c|c|c|c|c|c|c|}
\hline & & & & & $\begin{array}{c}\text { ignition } \\
\text { source, } \text { min-s }\end{array}$ & & & & \\
\hline \multicolumn{10}{|c|}{ Option 1} \\
\hline 1 & ML5 & $120 \times 10 \times 4,5$ & 1 & 45 & 2.31 & 10,40 & 8,50 & 18,3 & \multirow{5}{*}{$\begin{array}{l}\text { Melting, piece } \\
\text { of the sample } \\
\text { fell down }\end{array}$} \\
\hline 2 & ML5 & $120 \times 10 \times 4$ & 1 & 37 & 0.10 & 8,97 & 8,96 & 0,1 & \\
\hline 3 & OPBS & $120 \times 10,5 \times 4$ & 1 & 45 & 0.05 & 9,67 & 9,63 & 0,4 & \\
\hline 4 & OPBS & $120 \times 10,5 \times 3$ & 1 & 40 & 0.06 & 7,02 & 7,01 & 0,1 & \\
\hline 5 & OPBS & $120 \times 10,5 \times 3$ & 1 & 45 & 0.03 & 7,37 & 7,36 & 0,1 & \\
\hline \multicolumn{10}{|c|}{ Option 2} \\
\hline 1 & ML5 & $120 \times 10 \times 4$ & 2 & 45 & 0.03 & 10,37 & 8,47 & 18,3 & \multirow{2}{*}{$\begin{array}{l}\text { Melting, piece } \\
\text { of the sample } \\
\text { fell down }\end{array}$} \\
\hline 2 & OPBS & $120 \times 10,5 \times 4$ & 2 & 45 & 0.03 & 9,94 & 9,91 & 0,3 & \\
\hline \multicolumn{10}{|c|}{ Option 3} \\
\hline 1 & ML5 & $120 \times 10 \times 6$ & 2 & 95 & 2.45 & 14,83 & 0 & 100 & $\begin{array}{l}\text { Substrate burnt } \\
\text { out }\end{array}$ \\
\hline 2 & OPBS & $120 \times 10,5 \times 4,5$ & 2 & $\mathrm{HB}$ & 0 & 10,60 & 10,59 & 0,1 & $\begin{array}{l}\text { Melting, } \\
\text { sample } \\
\text { spreading on } \\
\text { the substrate }\end{array}$ \\
\hline \multicolumn{10}{|c|}{ Option 4} \\
\hline 1 & ML5 & $180 \times 10 \times 6$ & 2 & 54 & 1.01 & 20,57 & 18,46 & 10,3 & \multirow{2}{*}{$\begin{array}{l}\text { Melting, piece } \\
\text { of the sample } \\
\text { fell down }\end{array}$} \\
\hline 2 & OPBS & $180 \times 10 \times 5$ & 2 & $\mathrm{HB}$ & 0 & 17,04 & 17,03 & 0,1 & \\
\hline \multicolumn{10}{|c|}{ Option 5} \\
\hline 1 & ML5 & $180 \times 10 \times 6$ & 2 & 118 & 12.18 & 20,61 & 0 & 100 & - \\
\hline 2 & OPBS & $180 \times 10 \times 5$ & 2 & $\mathrm{HB}$ & 0 & 17,10 & 17,08 & 0,1 & $\begin{array}{c}\text { Melting, } \\
\text { sample } \\
\text { spreading on } \\
\text { the substrate }\end{array}$ \\
\hline 3 & OPBS & $180 \times 10 \times 5$ & 4 & 240 & 2.30 & 17,06 & 0 & 100 & - \\
\hline
\end{tabular}

It can be seen from the test results that with test options 1, 2 and 4, as the sample is heated by the burner flame, it melts and the melted part leaves the flame. The rest of the sample is exposed to temperature to a much lesser extent.

When testing samples on a non-combustible substrate (variants No. 3 and 5), the samples do not escape from the flame, but the intensity of their heating is significantly reduced.

Standard magnesium alloy ML5 with test variants No. 1 and 2, due to the sample melting and leaving the flame, can either ignite or fail to ignite. With test variant No. 4, the probability of escape from the flame is significantly lower, since the sample is fixed on both sides. Due to reflow, the weight loss of the sample due to burnout can range from 0.1 to $18 \%$. With test variants No. 3 and 5, this probability is absent due to the presence of the sample on the carrier substrate. The loss of mass of the sample in these cases is $80-100 \%$ (the residue of the samples may remain in the zone of contact with the fasteners).

The new experimental fire-safe alloy under test variants No. 1, 2, 3 and 4 either did not ignite at all, or went out within a few seconds $(3-5 \mathrm{sec})$, the loss of mass of the samples was no more than $0,4 \%$. Thus, a significantly higher fire safety of the new magnesium alloy is registered.

When testing a fireproof alloy according to option No. 5, when exposed to a burner flame for 2 minutes, the sample did not ignite, however, after 4 minutes of exposure to the flame and the removal of the burner flame from the sample, it ignited, prolonged combustion, ending with almost complete burnout. Thus, prolonged thermal exposure to the sample leads to its heating to temperatures close to $1000^{\circ} \mathrm{C}$. At these temperatures, the oxide layer formed on the surface is unable to prevent the contact of magnesium atoms with atmospheric oxygen, which leads to the occurrence of an exothermic oxidation reaction - heterogeneous combustion. 


\section{Conclusion}

A method for conducting fire tests for a comparative assessment of the ignition ability of magnesium alloys on small specimens has been developed.

Comparative flammability tests of two magnesium alloys when exposed to a burner flame with a temperature of $1100^{\circ} \mathrm{C}$ have been carried out.

It is shown that during testing of cantilevered specimens, part of the specimen often melts and falls out due to heating. As a result, the effect of the flame on the sample is practically stopped and the ignition of the sample may not occur. The samples do not escape from the flame if the sample has a supporting base; however, the use of the base complicates and slows down the heating of the sample.

It is shown that the samples of the experimental magnesium alloy, in comparison with the ML5 alloy, are more difficult to ignite and in most cases can self-extinguish rapidly, while the weight loss of the sample practically does not occur.

\section{References}

1. V.V. Antipov, Development strategy of titanium, magnesium, beryllium and aluminum alloys, Aviation materials and technologies, 2012. №S. P. 157-167

2. I.S. Kornysheva, Volkova E.F., Goncharenko E.S., Mukhina I.Yu., Prospects for the use of magnesium and casting aluminum alloys, Aviation materials and technologies, 2012. №S. P. 212-222

3. V.V. Antipov, Prospects for the development of aluminum, magnesium and titanium alloys for products of aerospace technology, Aviation materials and technologies, 2017. S. P. 186-194. DOI 10.18577/2071-9140-2017-0-S-186-194

4. V.A. Duyunova, Volkova E.F., Uridiya ZP, Trapeznikov A.V., Dynamics of development of magnesium and casting aluminum alloys, Aviation materials and technologies, 2017. №S. C. 225-241. DOI 10.18577/2071-9140-2017-0-S-225-241

5. A.Ya. Korolchenko, Korolchenko D.A., Fire and explosion hazard of substances and materials and means of their extinguishing, Pt.1 - 713 p., Pt.2-774 p.

6. V.I. Perelman, A reference book of a chemist, Moscow, 1951, 675 p.

7. E.F. Volkova, Barbot'ko S.L., Obrezkov O.I., Vershok B.A., A new solution to the problem of protection of magnesium alloys from ignition, Technology of light alloys, 2010. №1. P.151-156

8. S.V. Gnedenkov, Sidorova M.V., Sinebryukhov S.L., Antipov V.V., Buznik V.M., Volkova E.F., Sergienko V.I., Structure and properties of coatings obtained by plasma electrolytic oxidation on aviation magnesium alloys, Aviation materials and technologies, 2013. №S-2. P. 36-45

9. E.N. Kablov, Volkova E.F., Filonova E.V., Influence of REE on the phase composition and properties of a new high-temperature magnesium alloy of the Mg-Zn-Zr-REE system, Metallurgy and heat treatment of metals, 2017. №7(745). P. 19-26.

10. R. Tandon, Advances in Additive Manufacturing Using Magnesium Alloy Powders, The Eight Triennial International Aircraft Fire and Cabin Safety Research Conference, October 24-27, Atlantic City NJ https://www.fire.tc.faa.gov/2016Conference/files/Materials_VI_Magnesium/TandonAd ditiveMagAlloy/TandonAdditiveMagAlloyPres.pptx

11. B. Gwynne, Lyon P., Magnesium Alloys in Aerospace Applications, Past Concerns, Current Solutions, Triennial International Aircraft Fire \& Cabin Safety Research 
Conference, October 29 - November 1, 2007

https://www.fire.tc.faa.gov/2007Conference/files/Materials_Fire_Safety/WedAM/Gwy nneMagnesium/GwynneMagnesiumPres.pdf

12. Y. Kawamura, Flame-resistant Magnesium Alloys with High Strength, The Seventh Triennial International Fire \& Cabin Safety Research Conference / Philadelphia Marriott Downtown, December 2-5, 2013.

https://www.fire.tc.faa.gov/2013Conference/files/Magnesium_Use_In_Aircraft_I/Kaw amuraFireResistantMag/KawamuraFireResistantMagPres.pdf

13. D. Henry, Kemp M., Development of a Lightweight Forged Magnesium Aircraft Seat Component, Eighth Triennial International Aircraft Fire and Cabin Safety Research Conference / 27th October 2016

https://www.fire.tc.faa.gov/2016Conference/files/Crash_Dynamics_IV/HenryForgedM agnesium/HenryForgedMagnesiumPres.pdf

14. P. Boris, A study of the flammability of magnesium, Technical Report ADS-14 / Federal Aviation Agency, 1964, 43 p. https://www.fire.tc.faa.gov/pdf/ads-14.pdf

15. T.R. Marker, Evaluating the Flammability of Various Magnesium Alloys During Laboratory- and Full-Scale Aircraft Fire Tests, Technical Report DOT/FAA/AR-11/3 / Federal Aviation Administration, US Department of Transportation, 2013. 146 p. https://www.fire.tc.faa.gov/pdf/AR11-13.pdf

16. T.R. Marker, Development of a Laboratory-Scale Flammability Test for Magnesium Alloys Used in Aircraft Seat Construction, Technical Report DOT/FAA/TC-13/52 / Federal Aviation Administration, US Department of Transportation. 2014. 228 p. https://www.fire.tc.faa.gov/pdf/TC-13-52.pdf

17. T. Marker, Development of New Flammability Test for Magnesium-Alloy Cabin Components, International Aircraft Materials Fire Test Forum / Virtual Meeting, June 8, 2020 https://www.fire.tc.faa.gov/pdf/materials/June20Meeting/Marker-0620magtask.pdf

18. Aircraft Materials Fire Test Handbook https://www.fire.tc.faa.gov/Handbook

19. S.L. Barbot'ko, Volniy O.S., Kirienko O.A., Shurkova E.N., Assessment of fire safety of polymer materials for aviation purposes: analysis of the state, test methods, development prospects, methodological features, VIAM, 2018. $424 \mathrm{p}$.

20. E. Canary, Revised EASA SC on Use of Magnesium Alloys for Passenger Seat Components, International Aircraft Materials Fire Testing Working Group Meeting Cologne, 7-8 June 2017

https://www.fire.tc.faa.gov/pdf/materials/June17Meeting/EASA-0616UseofMagnesium.pdf

21. H.-P. Busch, Magnesium small scale test, FAA Seventh Triennial International Fire \& Cabin Safety Research Conference, 2-5 December, 2013 https://www.fire.tc.faa.gov/2013Conference/files/Magnesium_Use_in_Aircraft_II/Bus chMagBurning/BuschMagBurningPres.pptx

22. E.N. Kablov, Innovative developments of FSUE "VIAM" SSC RF for the implementation of "Strategic directions for the development of materials and technologies for their processing for the period up to 2030", Aviation materials and technologies. 2015. №1 (34). P. 3-33. DOI:10.18577/2071-9140-2015-0-1-3-33.

23. E.N. Kablov, New generation materials and technologies for their digital processing, Herald of the Russian Academy of Sciences. 2020. Vol. 90. No. 2. P. 225-228. 